\title{
The Treasury-Reserve Bank ATM Taskforce Report: Would it Pass a Cost-Benefit Analysis?
}

\author{
Hugh Green ${ }^{1}$
}

\section{Introduction}

In December 2010 the Commonwealth Government announced that the Reserve Bank of Australia and the Treasury would establish a joint 'ATM Taskforce' to analyse reforms to Australia's ATM market in 2009 which aimed to improve the competition and efficiency of the market by removing interchange fees on ATM transactions, replacing them with direct charges, while at the same time improving the information given to consumers about the costs of transactions at 'foreign' ATMs.

In May 2012 the Taskforce released its conclusions that these reforms have been 'overwhelmingly positive for the ATM market and for consumers', stating as support the magnitude of fee savings to ATM customers. Remarkably, in reaching this conclusion the Taskforce did not consider the reforms in the context of a formal cost-benefit analysis framework. To conclude that the reforms have been 'positive' implies that their benefits have outweighed their costs, which in turn involves summing the impacts of the reforms on all parties, both ATM owners and customers. Indeed, as stated in the Government's own Handbook of Cost Benefit Analysis, 'the aim [of cost-benefit analysis] is to measure the sum of changes in consumer and producer surplus'.$^{2}$ However, in analysing the effects of the reforms the Taskforce ignores their impact on the welfare (both direct and indirect) of ATM owners, focusing only on the impacts on consumers.

The result of this focus on consumer surplus is that any fee savings are seen as a positive, regardless of the effects they have on the welfare of the market as a whole. Further, the sole focus on fees masks the underlying resource costs at play. In particular, the travel costs faced by consumers and the differentials in processing costs between foreign and domestic transactions are crucial in determining optimal usage patterns.

1 The College of Business and Economics, The Australian National University, hugh.green@anu.edu.au

2 Department of Finance and Administration 2006: 22. Available at: http://www.finance.gov.au/publications/ finance-circulars/2006/01.html 
As I argued in the last issue of this journal (Green 2012), the reforms have in fact been welfare-destroying as they have led to an inefficient use of the ATM network. Consumer surplus has increased, but not by the full extent of the fee reductions due to the additional travel costs implied, while producer surplus has fallen by an amount close to the reduction in fees. Driving this result is the fact that fees are virtually unchanged, while the transparency effects of the reforms have alerted consumers to the inefficient price signals caused by foreign fees being excessively high relative to the price of 'domestic' transactions.

Despite this, the Taskforce concludes that competition in the market could be improved by further regulations to improve transparency. In this article I argue that the lack of a formal framework for analysis has led to this conclusion being misdirected. Further, the analysis could be better informed by recognising key results in the academic literature on ATM pricing. Just as the initial attempt at increasing fee transparency did not improve competition or efficiency, it is unlikely that furthering that regulation will achieve the desired results. Nonetheless, regulation of the ATM market is complex and, as the Taskforce argues, more direct regulation of fees poses its own challenges.

\section{The 2009 Reforms}

In March 2009 the Reserve Bank of Australia (RBA) implemented reforms to the Australian ATM market, aimed at improving competition and reducing perceived inefficiencies in the market at that time. There were two important aspects of these reforms. First, interchange fees between the ATM owner and the cardholder's financial institution were removed and replaced by the ATM owner directly charging the customer for the use of the machine. Second, the fee for this transaction was required to be displayed to the customer prior to the transaction being completed.

Prior to the reforms, most transactions at foreign ATMs attracted a fee of $\$ 2$, while transactions at domestic ATMs were free, with financial institutions instead preferring to recover costs through other account fees. This fee differential was significantly greater than the difference in processing costs between a foreign and domestic ATM which may amount to only a few cents. The result was an inefficiently low use of foreign ATMs relative to domestic ATMs. By moving to a system of direct charging it was hoped that competition for customers between ATM owners, who could now directly control the fee charged to the customer, would lead to a reduction in fees towards marginal cost. This would be aided by displaying fees at the point of transactions to inform consumers of the actual cost of a transaction, which was previously communicated to them through periodic bank statements. 
The outcomes of the reforms were somewhat different from their intention (Green 2012). Fees are, for all intents and purposes, unchanged now from what they were prior to the reforms, while there has actually been a shift away from foreign ATMs towards domestic machines (an increase from around 53-61 per cent of all transactions being conducted at domestic ATMs). The magnitude of this shift in dollar terms is significant, with the Taskforce reporting a reduction in foreign fees paid of $\$ 120$ million and $\$ 150$ million in the two years following the reforms.

\section{Analysis of the Taskforce's Conclusion}

Having reviewed the effects of the reforms, the Taskforce concludes:

In the view of the taskforce, the impact of the 2009 ATM reforms has been overwhelmingly positive for the ATM market and for consumers. On the demand side, consumers became well aware that it costs them something to conduct a foreign ATM transaction. They have responded accordingly by significantly reducing such transactions in preference to using their own ATMs and by finding alternatives, such as eftpos cashout. In this regard, the reforms have been very successful, reducing expenditure by at least $\$ 120$ million in the year following the reforms and a further $\$ 150$ million in the following year.

It seems strange to conclude that a market outcome has been improved when an overpriced product is used even less. So how has the Taskforce come to this conclusion? First, in assessing the impacts of the reform the Taskforce has not adopted a formal cost-benefit framework which would identify all impacted groups and compare the gains and losses to each. For example, the conclusion that the reforms have been 'very successful' because they have reduced fee expenditure by $\$ 150$ million is no more correct from an economic efficiency perspective than the statement that they have been very unsuccessful because they have reduced fee revenue to financial institution shareholders by $\$ 150$ million. Both perspectives consider the surplus of only one group in the market to the exclusion of the other.

The focus on fees, which are simply a transfer in a cost-benefit analysis and not a net welfare effect, abstracts from the real resource costs and benefits. In particular, as argued in Green (2012), consumers will have incurred significant travel costs in switching to using domestic ATMs instead of more convenient foreign machines. The Taskforce's report makes passing reference to these costs but does not include them in the formal analysis of the reforms. For example, in outlining why some consumers continue to use foreign ATMs the report concludes that 'this group appears to have made a judgement that the cost, in 
terms of time and effort, of locating and travelling to the nearest own-ATM exceeded the direct charge'. But it does not use the same logic to conclude that those who do make the switch still bear such a cost.

These costs need not be small. If the average consumer, who has as a result of the reforms switched to using domestic ATMs, incurs a travel cost of $\$ 1$ to save the $\$ 2$ fee then the fee saving of $\$ 150$ million corresponds to additional travel costs of $\$ 75$ million. The other resource cost to consider is the cost saving of processing more transactions through domestic rather than foreign ATMs. As noted above, this is non-zero but relatively small. Hence, as an order-ofmagnitude estimate, the reforms have likely led to net costs to the community in the tens of millions of dollars. Understandably, the Taskforce may place greater weight on the welfare of consumers than of shareholders. However, this preference would indeed need to be very heavily weighted towards consumers for the conclusion that the reforms have been successful to ring true.

An interesting question is why the fees have remained unchanged since the reforms and not fallen towards marginal cost, as envisaged. The Taskforce considered the level of competition in the market to be reasonable, indicating that the inflexibility could not be attributed to market power alone. On the transparency front, however, it suggests that consumers are still less than completely informed about ATM fees and this may be reducing the degree of price competition. For example, it states that 'while consumers are aware that foreign transactions incur direct charges, currently it is not made clear to them just what these charges are when approaching or passing by ATMs'.

Given this conclusion, the Taskforce argues that the price signals consumers receive are still insufficient to promote price competition between ATMs. It recommends improving the information customers receive about pricing by requiring ATM owners to display the foreign fee upfront rather than part way through the transaction, as currently occurs. However, the increased transparency achieved so far has had a clear effect on consumer decisions, with a large increase in the share of transactions conducted at domestic rather than foreign ATMs. Further, the fact that the vast majority of machines charge the same \$2 foreign fee makes it unlikely that consumers are not sufficiently informed of the cost of using foreign machines. Hence, a continuing lack of transparency does not seem to provide a satisfactory explanation for the rigidity of fees witnessed since the reforms.

The academic literature on ATM pricing does provide such an explanation. This literature points to the strategic use of ATMs by deposit-taking institutions to increase their market share for deposits. This article does not intend to provide a thorough review of the literature, ${ }^{3}$ but a couple of points are worth noting. 
First, the literature demonstrates that banks with a large number of ATMs may price foreign transactions significantly above domestic transactions as a way of increasing the cost of holding an account with a competing bank. Direct charging may facilitate this practice by providing banks with closer control over these fee differentials. ${ }^{4}$ Hence, an important conclusion from the literature is that ATMs cannot be considered as a separate market and that the strategic nature of their pricing means that the usual forces of competition cannot be expected to operate on them. Finally, the literature assumes that consumers are perfectly informed about ATM prices, implying that moves to improve transparency would not remove these strategic motives and may only move to strengthen them.

How seriously should these findings be taken? Given that there is no other clear explanation for the lack of movement in fees to date, the answer appears to be that the literature's conclusions should indeed be considered when designing future regulation. Further measures to increase transparency are unlikely to get at the core issues driving inefficiencies in the market and may only serve to continue or increase the large costs to society outlined above.

\section{Policy implications}

The lack of a formal analysis framework is not simply an academic point, as the conclusion that the reforms have been positive has led the Taskforce to conclude that the outcome could be further improved upon through additional measures to increase transparency. There is the impression that we are heading in the right direction but more of the same is required. In fact, if we consider the impacts of the reforms from a cost-benefit analysis perspective we are left to conclude that they have come at a net cost to the community.

So what should be done? The Taskforce considers the more heavy-handed approach of regulating ATM fees directly. It rightly argues against such regulation on the grounds that it may lead to unintended market consequences and could potentially lead to a less-efficient distribution of machines if machines from high-cost locations are removed or incentives to deploy additional machines are reduced.

An alternative form of price regulation not explored so far would be to regulate the differential directly, either by requiring banks to charge the same direct fee on domestic and foreign transactions, or tying this fee differential to a cost-based standard. ${ }^{5}$ This differential, which is based on strategic motivations, drives the

4 Donze and Dubec (2009).

5 Fees for independent ATM deployers would remain unregulated. 
decisions of consumers and is responsible for the inefficient use of the network currently observed. Further, as shown by Donze and Dubec (2009), it would be expected that ATM fees would fall as a result of this strategic motivation being removed. Finally, with more-efficient price signals in place, moves to improve transparency could then be justified.

Whichever approach is chosen, it should be informed by a formal framework in which the costs and benefits can be assessed. Weight should be placed on the surplus of both consumers and producers and consideration needs to be given to all resource costs. Finally, greater heed should be paid to the academic literature, which has provided strong insight into the reasons behind the rigidities present in the market.

\section{References}

Commonwealth of Australia 2006, 'Handbook of Cost Benefit Analysis'.

_ 2011, 'ATM Taskforce - Report on Transparency and Competition'.

Donze, J. and Dubec, I. 2009, 'Paying for ATM usage: good for consumers, bad for banks?' Journal of Industrial Economics 59: 583-612.

Green, H. 2012, 'Australia's 2009 ATM Reforms: Transparency for Transparency's Sake', Agenda 19(1): 5-16.

Noone, C. 2012, 'ATM Fees, Pricing and Consumer Behaviour: An Analysis of ATM Network Reform in Australia', RBA Research Discussion Paper, RDP2012-03. 